\title{
Avaliação in vitro da atividade antibacteriana de um cimento odontológico à base de óleo-resina de Copaifera multijuga Hayne
}

\author{
Kátia Regina Felizardo Vasconcelos, ${ }^{1}$ Valdir Florêncio da Veiga Junior, ${ }^{2}$ Waldireny Caldas \\ Rocha, ${ }^{3}$ Maria Fulgência Costa Lima Bandeira ${ }^{*, 4}$
}

${ }^{1}$ Programa de Mestrado em Patologia Tropical, Universidade Federal do Amazonas, Av Ayrão 1033A, 69025-005

Manaus-AM, Brasil,

${ }^{2}$ Departamento de Química, Universidade Federal do Amazonas, Av. Gal Rodrigo Octávio Jordão Ramos, 3.000, Japiim, 69077-000 Manaus-AM, Brasil,

${ }^{3}$ Centro de Biotecnologia da Amazônia, Laboratório de Fitoquímica, Av Gov. Danilo de Matos Areosa 690, 69075-351 Manaus-AM, Brasil,

${ }^{4}$ Faculdade de Odontologia, Universidade Federal do Amazonas, Av Ministro Waldemar Pedrosa, 1539, 69025-050 Manaus-AM, Brasil

\begin{abstract}
RESUMO: Um dos materiais utilizados para a adequação do meio bucal no serviço público é o cimento produzido a partir de óxido de zinco e eugenol. Entretanto, o eugenol é uma substância citotóxica que pode desencadear alguns efeitos adversos. Por essa razão, procura-se substituir o eugenol por uma substância que apresente baixa toxicidade, mantendo ou mesmo melhorando as propriedades do cimento. O óleo-resina de copaíba é um produto natural, utilizado pelas populações amazônicas e reconhecido por suas propriedades medicinais. Baseando-se nas propriedades desse óleo-resina, na ação antimicrobiana comprovada do hidróxido de cálcio e na ação anti-séptica do óxido de zinco, propôs-se formular um cimento odontológico obtido da associação do $\mathrm{ZnO}, \mathrm{Ca}(\mathrm{OH})_{2}$ e óleo-resina de Copaifera multijuga Hayne e avaliar sua atividade antibacteriana através do teste de diluição em meio líquido frente às cepas padrão de Streptococcus mutans (ATCC 25175) e S. sanguinis (ATCC 15300). Nesse ensaio, utilizaram-se os seguintes grupos experimentais: o cimento contendo $\mathrm{ZnO}, \mathrm{Ca}(\mathrm{OH})_{2}$ e óleo-resina de copaíba (G1) e cada um dos constituintes isoladamente, $\mathrm{ZnO}(\mathrm{G} 2), \mathrm{Ca}(\mathrm{OH})_{2}(\mathrm{G} 3)$ e óleo-resina de copaíba (G4). Todos os grupos analisados demonstraram atividade antibacteriana, o G4 apresentou os melhores resultados e o G1 mostrou-se um cimento promissor a ser utilizado em odontologia.
\end{abstract}

Unitermos: Óleo de copaíba, atividade antibacteriana, cimentos odontológicos, Copaifera multijuga, Fabaceae.

\begin{abstract}
In vitro assessment of antibacterial activity of a dental cement constituted of a Copaifera multijuga Hayne oil-resin”. One of the materials utilized for suitability of the oral means in the public service is the cement produced from zinc oxide and eugenol. However, eugenol is a cytotoxic substance that can trigger some adverse effects. For this reason, it is desired to replace eugenol for another substance that presents low toxicity, keeping or even improving the cement properties. The copaiba oil-resin is a natural product, utilized by the Amazonian population and recognized for its medicinal properties. Based on the properties of this oil-resin, on the proven antimicrobial activity of calcium hydroxide and on the anti-septic action of zinc oxide, it was proposed to formulate a dental cement obtained through the association of $\mathrm{ZnO}$, $\mathrm{Ca}(\mathrm{OH})_{2}$ and Copaifera multijuga Hayne oil-resin and assess its antibacterial activity through the test of dilution in aqueous medium against the standard of Streptococcus mutans (ATCC 25175) and S. sanguinis (ATCC 15300). In this assay, the following experimental groups were utilized: the cement containing $\mathrm{ZnO}, \mathrm{Ca}(\mathrm{OH})_{2}$ and copaiba oil-resin (G1) and each one of the constituents individually, $\mathrm{ZnO}(\mathrm{G} 2), \mathrm{Ca}(\mathrm{OH})_{2}(\mathrm{G} 3)$ and copaiba oil-resin (G4). All the analyzed groups showed antibacterial activity, G4 showed the best results and G1 showed itself to be a promising cement for application in dentristy.
\end{abstract}

Keywords: Copaiba oil, antibacterial activity, dental cements, Copaifera multijuga, Fabaceae.

\section{INTRODUÇÃO}

A cárie dental é reconhecida como uma doença infecto-contagiosa, de caráter multifatorial, que acomete cerca de $95 \%$ da população, necessitando do hospedeiro, da dieta cariogênica e da microbiota bucal, onde é fundamental o papel dos Streptococcus mutans no início da formação da cárie (Silva \& Nelson Filho, 
1994). Segundo Fejerskov \& Kidd (2005), além dos fatores biológicos relatados, os fatores sócio-econômicos influenciam na susceptibilidade do desenvolvimento da lesão de cárie.

A adequação do meio bucal consiste em um conjunto de procedimentos que visam a diminuição dos níveis de microrganismos cariogênicos, sendo a última etapa realizada através de restaurações provisórias das lesões cavitadas (Silva \& Nelson Filho, 1994). Sua realização é de suma importância antes de iniciar as atividades reabilitadoras necessárias ao restabelecimento da função e/ou da estética dos elementos dentários afetados por cavidades (Ribeiro \& Bussadori, 2000).

Tradicionalmente, utiliza-se o cimento composto por óxido de zinco e eugenol para adequação do meio bucal em odontologia. Entretanto, o eugenol é uma substância citotóxica, que pode desencadear a degeneração dos tecidos moles e morte de fibroblastos, além de dermatite de contato e reações alérgicas (Barkin et al., 1984; Sarrami et al., 2002). De acordo com Watts \& Patterson (1987), a reação inflamatória persistente, necrose pulpar e ausência de reparo foram observadas após o uso desse cimento em exposições pulpares de ratos.

Por essa razão, tem-se procurado uma substituição ao eugenol, devido seu potencial irritativo, buscando uma nova substância com baixa toxicidade, atividade antibacteriana, acessível e de confiabilidade para o cirurgião-dentista (Bandeira et al., 1999a). Além disso, o consumidor tem se tornado cada vez mais exigente com a qualidade dos produtos que utiliza, sendo crescente a sua preocupação em fazer uso de produtos menos agressivos de origem natural (Packer \& Luz, 2007).

O óleo-resina de copaíba é um produto extraído de várias espécies do gênero Copaifera (Veiga Junior \& Pinto, 2002) e utilizado há muito tempo pelos índios para tratamento de feridas, devido aos seus efeitos antiinflamatórios (Veiga Junior et al., 2001; Veiga Junior et al., 2006; Veiga Junior et al., 2007; Agra et al., 2007; 2008), antitumorais (Lima et al., 2003), antisépticos (Bruneton, 1987), ação germicida (Bloise, 2003; Biavatti et al., 2006), antibacterianos (Opdyke, 1976; Lima et al., 1995; Bandeira, 1998; Miranda et al., 2000) Santos et al., 2008) e antifúngico (Abinader, 2005; Bandeira et al., 2006).

A espécie Copaifera multijuga Hayne pertence à família Fabaceae, subfamília Caesalpinioideae. Em uma área de plantação desta espécie na Reserva Adolfo Ducke, do Instituto Nacional de Pesquisas da Amazônia (INPA), em Manaus, árvores de grande porte atingem até $36 \mathrm{~m}$ de altura com diâmetro de até $80 \mathrm{~cm}$. Muitos dos trabalhos realizados com o gênero Copaifera estão relacionados com o óleo-resina que é obtido do tronco destas árvores. Segundo alguns autores, esse óleo é produto da desintoxicação do organismo vegetal e funciona como defesa da planta contra animais, fungos e bactérias (Bandeira et al., 1999b; Veiga Junior et al., 2001; Veiga Junior \& Pinto, 2002). As espécies desse gênero que produzem óleo-resina em quantidades apreciáveis são encontradas nas regiões tropicais da América do Sul, como o Brasil, a Venezuela e a Colômbia, com maior incidência no Brasil, onde apresentam ampla distribuição na terra firme da Amazônia (Alencar, 1981; Veiga Junior et al., 2001; Veiga Junior \& Pinto, 2002).

Segundo Bandeira et al., (1999b), o óleoresina de C. multijuga apresenta em sua composição vários sesquiterpenos, principalmente $\beta$-cariofileno, $\alpha$-humuleno, cedreno, cadineno e bisaboleno.

Almeida (1998); Bandeira (1998; 2000); Garrido (2004) e Abinader (2005) comprovaram ser possível a associação entre o óleo-resina de copaíba, óxido de zinco e hidróxido de cálcio, propondo novos estudos para que essa associação pudesse ser utilizada em odontologia.

Estudos demonstraram atividade antibacteriana do óleo-resina de Copaifera multijuga Hayne frente aos Streptococcus mutans e Streptococcus sanguinis (Bandeira, 1998; Simões, 2004; Vasconcelos, 2006).

Analisando as propriedades medicinais do óleo da Copaifera multijuga Hayne e os resultados encontrados por Bandeira et al., (1999a; 1999b), Simões (2004), Storck (2004), Garrido (2004), Garrido et al., (2004) e Abinader (2005), este trabalho tem por objetivo formular um cimento odontológico à base de óleo-resina de Copaifera multijuga Hayne, avaliando sua atividade antibacteriana frente a cepas de Streptococcus mutans e Streptococcus sanguinis, visando sua posterior utilização para adequação do meio bucal em odontologia.

\section{MATERIAL E MÉTODOS}

\section{Obtenção do óleo}

O óleo-resina da Copaifera multijuga Hayne estudado foi obtido da Reserva Adolfo Ducke, do Instituto Nacional de Pesquisas da Amazônia (INPA), localizada no Km 17 da Rodovia Manaus-Itacoatiara, no Estado do Amazonas, da espécie catalogada sob o $n^{\circ} 69$. A coleta do óleo-resina foi realizada em setembro de 2006.

\section{Análises cromatográficas}

Para a identificação dos constituintes do óleo de copaíba foi realizada a análise por meio de cromatografia em fase gasosa acoplada a detector de ionização de chama (CG-DIC) e a detector de espectrometria de massas (CG-EM). Anteriormente a todas as análises cromatográficas realizadas o óleo de copaíba sofreu uma modificação química de forma a adequar sua polaridade às necessidades do sistema cromatográfico utilizado. O óleo foi mantido em contato com solução recémpreparada de diazometano dissolvido em éter, de forma 
a produzir a esterificação dos grupamentos carboxila dos ácidos diterpênicos presentes no óleo. Para as análises de CG-DIC foi utilizado um cromatógrafo em fase gasosa modelo Hewlett-Packard HP-6890 com injetor automático Agilent 7893B em split 1:20 com injetor a $220{ }^{\circ} \mathrm{C}$, gás de arraste $\mathrm{H}_{2}$ a $3,6 \mathrm{ml} / \mathrm{min}$, detectores a 270 ${ }^{\circ} \mathrm{C}$, com duas colunas cromatográficas HP-INNOWAX, de $30 \mathrm{~m}$ de comprimento, 0,320 $\mathrm{m}$ de diâmetro interno e 0,25 um de espessura de fase e HP-5 (5\% fenil em metil siloxano), de $30 \mathrm{~m}$ de comprimento, $0,320 \mathrm{~m}$ de diâmetro interno e 0,25 um de espessura de fase.

Utilizou-se um Cromatógrafo à Gás Varian, modelo 3900; um Espectrômetro de Massas Varian, modelo Íon Trap 2000; um software de busca com biblioteca NIST, Wiley e um software Saturno $2100 \mathrm{~T}$ GC/MS. O sistema de análise utilizado para programação do cromatógrafo em fase gasosa apresentou temperatura do injetor $270{ }^{\circ} \mathrm{C}$, Split 1:20, fluxo de hélio na coluna 2,0 $\mathrm{mL} \mathrm{min}^{-1}$, programação de temperatura do forno com temperatura inicial $110^{\circ} \mathrm{C}$ até $140^{\circ} \mathrm{C}$ com razão de aquecimento de $2{ }^{\circ} \mathrm{C} \min ^{-1}, 140{ }^{\circ} \mathrm{C}$ a $290{ }^{\circ} \mathrm{C}$ com razão de aquecimento de $8{ }^{\circ} \mathrm{C} \mathrm{min}-1$, tempo de corrida $35 \mathrm{~min}$, coluna VF-1ms LB com $30 \mathrm{~m}$ x 25 mm x 0,25 $\mu \mathrm{m}$, fase estacionária $100 \%$ metil polisiloxano. A programação do espectrômetro de massas apresentou temperaturas de linha transferência em $200{ }^{\circ} \mathrm{C}$, mainfold $50^{\circ} \mathrm{C}$ e trap em $190{ }^{\circ} \mathrm{C}$, range de $\mathrm{m} / \mathrm{z}$ de 40 a 500 u.m.a. e ionização por impacto de elétrons $(70 \mathrm{eV})$.

\section{Formulação do cimento}

Para a formulação do cimento foram utilizados 0,57 g de óxido de zinco (SS White ${ }^{\circledR}$, Brasil), 0,18 g de hidróxido de cálcio (SS White ${ }^{\circledR}$, Brasil) e $0,118 \mathrm{~mL}$ de óleo-resina de Copaifera multijuga Hayne, visando obter um cimento com consistência espessa e homogênea, ideal para aplicação como cimento provisório na clínica odontológica.

\section{Determinação do $\mathrm{pH}$ do cimento}

A medida do $\mathrm{pH}$ do cimento e seus componentes foi realizada segundo Leonardo et al., (1992), de acordo com os grupos a seguir:

Óleo-resina de Copaifera multijuga Hayne + óxido de zinco + hidróxido de cálcio (cimento);

Óleo-resina de Copaifera multijuga Hayne + hidróxido de cálcio (pasta); óxido de zinco (pasta);

Óleo-resina de Copaifera multijuga Hayne +

Óleo-resina de Copaifera multijuga Hayne.

Foram pesados 1,5 g dos compostos (cimento e pastas) em balança de precisão (Sartorius ${ }^{\circledR}$, EUA) e, em seguida, diluídos em $6 \mathrm{~mL}$ de água destilada. Agitouse as soluções em Vortex por 15 minutos e aferiu-se o pH com auxílio de fitas indicadoras de pH $\left(\right.$ Merck $^{\circledR}$, Alemanha).

\section{Determinação da concentração inibitória mínima}

A concentração inibitória mínima (CIM) foi determinada tendo como base o método de diluição em meio líquido preconizado por Andrews (2001) e modificado por Abinader (2005), segundo as normas do NCCLS (2002). Foram utilizadas cepas padrão de Streptococcus mutans ATCC 25175 e Streptococcus sanguinis ATCC 15300, disponibilizadas para a pesquisa pelo Instituto Nacional de Controle de Qualidade em Saúde (INCQS-Fiocruz, RJ).

$\mathrm{O}$ crescimento bacteriano foi obtido em fase exponencial, no período de 24 horas em placa de Petri, em microaerofilia a $37 \pm 1{ }^{\circ} \mathrm{C}$. Em condições assépticas, foram retiradas alíquotas dos microrganismos coletados com alça de platina com $5 \mathrm{~mm}$ de diâmetro para inoculação em $5 \mathrm{~mL}$ de solução salina estéril em tubos de ensaio de $10 \times 150 \mathrm{~mm}$. Os preparados foram turbilhonados em Vortex até a obtenção de uma suspensão homogênea. As suspensões foram padronizadas pela escala \#0,5 de McFarland.

Para a realização do ensaio foram utilizados os seguintes grupos experimentais:

(G1) - Óleo-resina de Copaifera multijuga Hayne + óxido de zinco + hidróxido de cálcio (cimento);

(G2) - Óxido de zinco - (ZnO);

(G3) - Hidróxido de cálcio - $\mathrm{Ca}(\mathrm{OH})_{2}$

(G4) - Óleo-resina de Copaifera multijuga

Hayne;

Os experimentos foram realizados em tubos de ensaio estéreis de 19,8 x 1,8 milímetros. Cada tubo continha o meio de cultura (caldo BHI), o grupo experimental e o inóculo. Uma solução inicial foi preparada com o grupo experimental (G1), contendo 0,57 g de óxido de zinco, 0,18 g de hidróxido de cálcio e 0,118 mL de óleo-resina de copaíba, além de 0,05 mL de inóculo e o meio líquido, ajustado para totalizar $10 \mathrm{~mL}$. Foram realizadas diluições sucessivas a $50 \%$ da solução inicial, obtendo-se cinco diluições nos 6 tubos (A-F), em que, para o óxido de zinco, por exemplo, utilizou-se $0,57 \mathrm{~g}$ no grupo experimental do tubo A e, ao final das diluições, 0,017 g no tubo F (Tabela 1).

Como controle positivo foi utilizada uma solução contendo apenas $9,95 \mathrm{~mL}$ de meio de cultura e 0,05 mL de inóculo bacteriano. Em todos os experimentos foi utilizado também um controle negativo, contendo apenas os $10 \mathrm{~mL}$ do meio de cultura.

De forma a avaliar se a atividade antibacteriana observada foi originada pelo grupo experimental G1 ou por apenas algum de seus constituintes, isoladamente, foram realizados experimentos utilizando apenas óxido de zinco, hidróxido de cálcio ou óleo de copaíba como grupos experimentais, denominados G2, G3 e G4, respectivamente. Nesses experimentos foram utilizadas as mesmas quantidades dos três materiais analisados inicialmente, 0,05 mL de inóculo e meio de cultura, 
Tabela 1. Quantidade total dos componentes (g/mL) para cada grupo experimental.

\begin{tabular}{|c|c|c|c|c|c|c|c|c|}
\hline Diluição & \multicolumn{2}{|c|}{ G1 } & \multicolumn{2}{|c|}{ G2 } & \multicolumn{2}{|c|}{ G3 } & \multicolumn{2}{|l|}{ G4 } \\
\hline A & $\begin{array}{l}\mathrm{ZnO}(\mathrm{g}) \\
\mathrm{Ca}(\mathrm{OH})_{2}(\mathrm{~g}) \\
\text { Copaíba (mL) }\end{array}$ & $\begin{array}{l}0,57 \\
0,18 \\
0,118 \\
\end{array}$ & $\mathrm{ZnO}(\mathrm{g})$ & 0,57 & $\mathrm{Ca}(\mathrm{OH})_{2}(\mathrm{~g})$ & 0,18 & $\begin{array}{r}- \\
- \\
\text { Copaíba (mL) }\end{array}$ & 0,118 \\
\hline B & $\begin{array}{l}\mathrm{ZnO}(\mathrm{g}) \\
\mathrm{Ca}(\mathrm{OH})_{2}(\mathrm{~g}) \\
\text { Copaíba (mL) }\end{array}$ & $\begin{array}{c}0,285 \\
0,09 \\
0,059 \\
\end{array}$ & $\mathrm{ZnO}(\mathrm{g})$ & 0,285 & $\mathrm{Ca}(\mathrm{OH})_{2}(\mathrm{~g})^{-}$ & 0,09 & Copaíba $(\mathrm{mL})$ & 0,059 \\
\hline $\mathrm{C}$ & $\begin{array}{l}\mathrm{ZnO}(\mathrm{g}) \\
\mathrm{Ca}(\mathrm{OH})_{2}(\mathrm{~g}) \\
\text { Copaíba }(\mathrm{mL})\end{array}$ & $\begin{array}{c}0,14 \\
0,045 \\
0,029 \\
\end{array}$ & $\mathrm{ZnO}(\mathrm{g})$ & 0,14 & $\mathrm{Ca}(\mathrm{OH})_{2}(\mathrm{~g})$ & 0,045 & Copaíba $(\mathrm{mL})$ & 0,029 \\
\hline D & $\begin{array}{l}\mathrm{ZnO}(\mathrm{g}) \\
\mathrm{Ca}(\mathrm{OH})_{2}(\mathrm{~g}) \\
\text { Copaíba }(\mathrm{mL})\end{array}$ & $\begin{array}{c}0,071 \\
0,022 \\
0,014 \\
\end{array}$ & $\mathrm{ZnO}(\mathrm{g})$ & 0,071 & $\mathrm{Ca}(\mathrm{OH})_{2}(\mathrm{~g})$ & 0,022 & Copaíba $(\mathrm{mL})$ & 0,014 \\
\hline E & $\begin{array}{l}\mathrm{ZnO}(\mathrm{g}) \\
\mathrm{Ca}(\mathrm{OH})_{2}(\mathrm{~g}) \\
\text { Copaíba }(\mathrm{mL})\end{array}$ & $\begin{array}{c}0,035 \\
0,011 \\
0,007 \\
\end{array}$ & $\mathrm{ZnO}(\mathrm{g})$ & 0,035 & $\mathrm{Ca}(\mathrm{OH})_{2}(\mathrm{~g})_{-}^{-}$ & 0,011 & $\begin{array}{r}- \\
- \\
\text { Copaíba }(\mathrm{mL})\end{array}$ & 0,007 \\
\hline $\mathrm{F}$ & $\begin{array}{l}\mathrm{ZnO}(\mathrm{g}) \\
\mathrm{Ca}(\mathrm{OH})_{2}(\mathrm{~g}) \\
\text { Copaíba }(\mathrm{mL})\end{array}$ & $\begin{array}{c}0,017 \\
0,005 \\
0,003 \\
\end{array}$ & $\mathrm{ZnO}(\mathrm{g})$ & 0,017 & $\mathrm{Ca}(\mathrm{OH})_{2}(\mathrm{~g})^{-}$ & 0,005 & $\begin{array}{r}- \\
- \\
\text { Copaíba }(\mathrm{mL}) \\
\end{array}$ & 0,003 \\
\hline
\end{tabular}

Tabela 2. Concentração inibitória mínima das diluições frente aos S. mutans e S. sanguinis nos tempos de 24 e 48 horas.

\begin{tabular}{|c|c|c|c|c|c|c|c|c|c|c|c|c|c|c|c|c|}
\hline \multirow{3}{*}{ Diluição } & \multicolumn{4}{|c|}{ G1 } & \multicolumn{4}{|c|}{ G2 } & \multicolumn{4}{|c|}{ G3 } & \multicolumn{4}{|c|}{ G4 } \\
\hline & \multicolumn{2}{|c|}{ S. mutans } & \multicolumn{2}{|c|}{ S. sanguinis } & \multicolumn{2}{|c|}{ S. mutans } & \multicolumn{2}{|c|}{ S. sanguinis } & \multicolumn{2}{|c|}{ S. mutans } & \multicolumn{2}{|c|}{ S. sanguinis } & \multicolumn{2}{|c|}{ S. mutans } & \multicolumn{2}{|c|}{ S. sanguinis } \\
\hline & $24 \mathrm{~h}$ & $48 \mathrm{~h}$ & $24 \mathrm{~h}$ & $48 \mathrm{~h}$ & $24 \mathrm{~h}$ & $48 \mathrm{~h}$ & $24 \mathrm{~h}$ & $48 \mathrm{~h}$ & $24 \mathrm{~h}$ & $48 \mathrm{~h}$ & $24 \mathrm{~h}$ & $48 \mathrm{~h}$ & $24 \mathrm{~h}$ & $48 \mathrm{~h}$ & $24 \mathrm{~h}$ & $48 \mathrm{~h}$ \\
\hline A & - & - & - & - & - & - & - & - & - & - & - & - & - & - & - & - \\
\hline B (1:2) & - & - & - & - & - & - & - & - & - & - & - & - & - & - & - & - \\
\hline C (1:4) & - & + & - & + & - & + & - & - & - & - & - & + & - & - & - & - \\
\hline $\mathrm{D}(1: 8)$ & - & + & - & + & - & + & - & + & - & - & - & + & - & - & - & - \\
\hline E $(1: 16)$ & - & + & - & + & - & + & - & + & - & + & + & + & - & - & - & - \\
\hline $\mathrm{F}(1: 32)$ & - & + & - & + & - & + & + & + & - & + & + & + & - & - & - & - \\
\hline
\end{tabular}

+ crescimento bacteriano positivo; - crescimento bacteriano negativo.

completando os $10 \mathrm{~mL}$, sempre em 6 experimentos diferentes (A-F), com as cinco diluições descritas anteriormente (Tabela 1).

Antes da incubação os tubos foram agitados em Vortex para homogeneização das substâncias testadas com o meio de cultura. Em seguida, foram incubados em estufa bacteriológica por 24 horas a $37 \pm 1{ }^{\circ} \mathrm{C}$, em microaerofilia.

Após as 24 horas de incubação, semeou-se com o auxílio de um swab, o conteúdo de cada um dos tubos em placas de Petri, divididas em quatro quadrantes onde cada quadrante correspondia a uma diluição. As placas foram, então, incubadas em microaerofilia e o crescimento bacteriano observado após 24 e 48 horas. Os quadrantes que não apresentaram crescimento bacteriano foram considerados negativos e os que apresentaram crescimento foram considerados positivos.

A CIM foi considerada a menor concentração capaz de inibir $100 \%$ do crescimento bacteriano, tendo como referência o seu respectivo controle positivo.

\section{RESULTADOS E DISCUSSÃO}

O gênero Streptococcus foi o escolhido para esse experimento uma vez que é o gênero bacteriano predominante desde o nascimento até a morte do indivíduo e, segundo Uzeda (2002), a superfície coronária dos dentes representa uma área favorável à colonização e implantação de Streptococcus mutans e Streptococcus sanguinis.

Os resultados da análise cromatográfica do óleo-resina da Copaifera multijuga Hayne revelaram que entre os seus componentes estão vários sesquiterpenos, principalmente $\beta$-cariofileno (9,2\%), $\alpha$-humuleno $(1,8 \%)$, germacreno $\mathrm{D}(3,5 \%)$, óxido de cariofileno (11,5\%), cubenol (16,7\%) e bisabolol (7,2\%) e também diterpenos de esqueleto labdano, como os ácidos copálico (2,1\%), 3ß-hidróxi-copálico (1,7\%) e pinifólico (1,3\%). Esses resultados foram semelhantes aos encontrados por vários autores (Bandeira, 1998; Cascon \& Gilbert, 2000; Bandeira, 2000; Veiga Jr \& Pinto, 2002, Lima et al., 2003 e Simões, 2004).

As análises do $\mathrm{pH}$ das soluções mostraram que a de maior $\mathrm{pH}(9,5)$ foi a da associação $\mathrm{Ca}(\mathrm{OH})_{2}$ + óleo-resina de Copaifera multijuga Hayne, seguida da associação de $\mathrm{ZnO}$ + óleo-resina de Copaifera multijuga Hayne $(\mathrm{pH}=6,5)$. $\mathrm{O} \mathrm{pH}$ do óleo-resina de Copaifera multijuga Hayne foi de 4,5 confirmando os 
achados de Trease (1983), Bandeira (1998), Simões (2004) e Abinader (2005) que afirmaram que o óleoresina de copaíba apresentou característica ácida de $\mathrm{pH}$, enquanto que o $\mathrm{pH}$ do cimento G1 foi de 10, o que para o gênero Streptococcus proporcionaria um meio com pH de difícil crescimento (Cruz et al., 2001).

A CIM foi obtida para cada grupo experimental e os resultados analisados através de estatística descritiva.

Os resultados obtidos foram promissores, mostrando que o cimento G1 apresentou atividade antibacteriana mesmo em quantidades muito pequenas. Frente ao $S$. mutans e ao $S$. sanguinis mostrou atividade antibacteriana em todas as diluições analisadas no tempo de 24 horas, e em 48 horas, a concentração inibitória mínima foi até a diluição de 1:2, mostrando que a atividade antibacteriana foi proporcional à concentração do cimento (Tabela 2).

A inibição dos microrganismos ocorreu em todos os grupos testados. O óxido de zinco (G2) apresentou atividade antibacteriana frente ao $S$. mutans em todas as diluições analisadas e frente ao $S$. sanguinis a inibição foi até a diluição de 1:16, no tempo de 24 horas. Em 48 horas, a concentração inibitória mínima foi até a diluição $1: 2$, frente ao $S$. mutans, e até a diluição 1:4, frente ao $S$. sanguinis. Esse resultado é condizente com o observado por Bandeira (1998), que demonstrou atividade bactericida do óxido de zinco até a concentração de $50 \mathrm{mg} / \mathrm{mL}$.

Outro componente do cimento testado isoladamente foi o hidróxido de cálcio (G3), o qual foi capaz de inibir o S. mutans em todas as diluições testadas e frente ao $S$. sanguinis até a diluição 1:8, no período de 24 horas. Em 48 horas, a concentração inibitória mínima foi até a diluição de $1: 8$, frente ao $S$. mutans e até a diluição $1: 2$, frente ao $S$. sanguinis.

Os componentes do cimento analisados isoladamente (G2, G3 e G4) apresentaram-se com capacidade de inibir as duas bactérias. Os espectros de ação dos grupos 2 e 3 foram muito semelhantes, porém a ação antibacteriana do óleo de copaíba (G4) se diferenciou por apresentar eficiência mesmo quando em pequena concentração.

O óleo de copaíba (G4) apresentou o melhor desempenho frente aos microrganismos analisados, com as vantagens de ser um produto natural e de menor custo. Sua capacidade de inibir as duas bactérias em todas as diluições analisadas demonstrou a atividade antibacteriana desse óleo-resina, conforme já anteriormente observado por outros autores (Marussella \& Sicurella, 1960; Opdyke, 1976; Lima et al., 1995; Bandeira, 1998; Miranda et al., 2000; Cascon \& Gilbert, 2000; Garrido et al., 2004 e Abinader, 2005).

\section{CONCLUSÃO}

O óleo-resina de Copaifera multijuga Hayne

e o cimento produzido apresentaram atividade antibacteriana frente ao $S$. mutans e ao $S$. sanguinis no teste de diluição em meio líquido, portanto o óleo de copaíba apresentou-se com grande potencial para o uso como veículo ao cimento.

O cimento mostrou-se um material promissor a ser utilizado em odontologia, necessitando de estudos posteriores no que tange a propriedades físico-químicas e de biocompatibilidade.

\section{REFERÊNCIAS}

Abinader CD 2005. Avaliação in vitro da atividade antimicrobiana da pasta de hidróxido de cálcio associada a diferentes veículos frente a Candida albicans e ao Enterococcus faecalis. Manaus, 143p. Dissertação de Mestrado em Patologia Tropical - Faculdade de Ciências da Saúde, Universidade Federal do Amazonas.

Agra MF, França PF, Barbosa-Filho JM 2007. Synopsis of the plants known as medicinal and poisonous in Northeast of Brazil. Rev Bras Farmacogn 17: 114140.

Agra MF, Silva KN, Basílio IJLD, França PF, Barbosa-Filho JM 2008. Survey of medicinal plants used in the region Northeast of Brazil. Rev Bras Farmacogn 18: 472-508.

Alencar JC 1981. Estudos silviculturais de uma população natural de Copaifera multijuga Hayne - Leguminosae na Amazônia Central. 1 - Germinação. Acta Amazônica 11: 3-11.

Almeida FR 1998. Avaliação do $\mathrm{pH}$, tempo de presa e atividade antimicrobiana do óleo de copaíba, associado a pós de cimentos odontológicos. Brasília, 93p. Dissertação de Mestrado em Ciências da Saúde - Faculdade de Ciências da Saúde, Universidade de Brasília.

Andrews JM 2001. Determination of minimum inhibitory concentrations. J Antimicrobial Chemother 48: 5-16.

Bandeira MFCL 1998. Estudo comparativo da compatibilidade biológica do óleo essencial e da resina da Copaifera multijuga, associados ao hidróxido de cálcio, em diferentes níveis de pesquisa: farmacológico, microbiológico e molares de rato. Araraquara, 265 p. Dissertação de Mestrado em Dentística Restauradora - Faculdade de Odontologia, Universidade Estadual Paulista.

Bandeira MFCL, Oliveira MRB, Benatti-Neto C, Camelli Lia RC 1999a. Estudo comparativo da compatibilidade biológica em molares de rato do óleo essencial e da resina da Copaifera multijuga (óleo de copaíba) associados ao hidróxido de cálcio. J Bras Clin Estet Odontol 3: 42-49.

Bandeira MFCL, Oliveira MRB, Pizzolito AC, BenattiNeto C, Jorge-Neto J 1999b. Estudo farmacológico preliminar de Copaifera multijuga (óleo de copaíba). J Bras Clin Estet Odontol 3: 39-41.

Bandeira MFCL 2000. Análise comparativa sobre a compatibilidade biológica do óleo essencial e do óleo in natura da Copaifera multijuga (óleo de copaíba), associados ao hidróxido de cálcio em capeamento pulpar em dentes de cães. Araraquara, 205p. Tese de Doutorado - Faculdade de Odontologia, Universidade 
Estadual Paulista.

Bandeira MFCL, Texeira MFS, Abinader CD, Parente RC, Lima PSL 2006. Avaliação in vitro da sensibilidade da Candida albicans ao hidróxido de cálcio associado ao óleo de copaíba. Rev Dentística on line 13: 1222.

Barkin ME, Boyd JP, Cohen S 1984. Acute allergic reaction to eugenol. Oral Surg Oral Med Oral Pathol 57: 441442.

Biavatti MW, Dossin D, Deschamps FC, Lima MP 2006. Análise de óleos-resinas de copaíba: contribuição para o seu controle de qualidade. Rev Bras Farmacogn 16: 230-235.

Bloise MI 2003. Óleos vegetais e especialidades da floresta Amazônica. Cosmetics \& Toiletries 15: 46-49.

Bruneton J 1987. Eléments de phytochimie et de Pharmacognosie. Paris: Lavoisier.

Cascon V, Gilbert B 2000. Characterization of the chemical composition of oleoresins of Copaifera guianensis Desf., Copaifera duckei Dwyer and Copaifera multijuga Hayne. Phytochemistry 55: 773-778.

Cruz CW, Moura PPR, Habitante SM, Zöllner N, Jorge AOC 2001. Avaliação do efeito antibacteriano in vitro dos cimentos obturadores Rickert, N-Rickert e Sealer 26. Rev Biociências 7: 49-53.

Fejerskov O, Kidd E 2005. Cárie dentária - a doença e seu tratamento clínico. São Paulo: Santos.

Garrido ADB 2004. Estudo comparativo da biocompatibilidade e propriedades físico-químicas de um novo cimento endodôntico. Manaus, 381p. Tese de Doutorado Universidade Federal do Amazonas.

Garrido ADB, Lia RCC, Torres SCZ, Fonseca TS, Pereira JV, Sponchiado-Jr EC, França SC 2004. Avaliação da atividade antimicrobiana de amostras do óleoresina da copaíba em microrganismos da microbiota endodôntica. Sociedade Brasileira de Pesquisa Odontológica. Águas de Lindóia, Brasil.

Leonardo MR, Reis RT, Silva LAB, Loffredo LCM 1992. Hidróxido de cálcio em endodontia: Avaliação da alteração de pH e da liberação de íons de cálcio em produtos endodônticos à base de hidróxido de cálcio. RGO 40: 69-72.

Lima LS, Torkasky RM, Psiciottano NC, Santos AM, Schumacker IE 1995. Plantas medicinais. Cosmetics \& Toiletries 7: 39.

Lima SRM, Veiga Junior VF, Christo HB, Pinto AC, Fernandes PD 2003. In vivo and in vitro studies on the anticancer activity of Copaifera multijuga Hayne and its fractions. Phytother Res 17: 1048-1053.

Marussella JC, Sicurella NA 1960. Antibacterial activity of essential oil vapors. J Am Pharm Assoc 49: 692-694.

Miranda RCM, Wanderley TKV, Moura W, Araújo JM 2000. Atividade antimicrobiana do óleo de copaíba (Copaifera spp.) de diferentes procedências. XVI Simpósio de Plantas Medicinais do Brasil. Recife, Brasil.

NCCLS 2002. National Comittee for Clinical Laboratory Standards, Performance Standards for Antimicrobial Suceptibility testing; Twelth informational suplement M100-512, vol. 22, n 01., 2002.

Opdyke DLJ 1976. Balsam Copaiba. Food and Cosmetics Toxicology 14: 687.

Packer JF, Luz MMS 2007. Método para avaliação e pesquisa da atividade antimicrobiana de produtos de origem natural. Rev Bras Farmacogn 17: 102-107.

Ribeiro SK, Bussadori SK 2000. Comparação entre o gel de clorexidina e o verniz de flúor na contagem salivar de S. mutans. Rev Paul Odontol 22: 48-52.

Santos AO, Ueda-Nakamura T, Dias Filho BP, Veiga Junior, VF, Pinto AC, Nakamura CV 2008. Antimicrobial activity of Brazilian copaiba oils obtained from different species of the Copaifera genus. Mem Inst Oswaldo Cruz 103: 227-281.

Sarrami N, Pemberton MN, Thornhill MH, Theaker ED 2002. Adverse reactions associated with the use of eugenol in dentistry. Braz Dent J 193: 257-259.

Silva LAB, Nelson Filho P 1994. Adequação do meio bucal. Jornal da AORP 56: 8.

Simões CACG 2004. Formulação de um gel de óleo de copaíba (Copaifera multijuga) e avaliação de sua atividade antibacteriana sobre cepas de Streptococcus sp. isoladas da placa dental. Manaus, 120p. Dissertação de Mestrado em Patologia Tropical - Faculdade de Ciências da Saúde, Universidade Federal do Amazonas.

Storck LML 2004. Avaliação da compatibilidade biológica do gel elaborado da Copaifera multijuga no epitélio gengival de ratos. Manaus, 77p. Dissertação de Mestrado em Patologia Tropical - Faculdade de Ciências da Saúde, Universidade Federal do Amazonas.

Trease GE 1983. Pharmacology. Rio de Janeiro: Bailiere Tindall.

Uzeda M 2002. Microbiologia Oral - Etiologia da Cárie, Doença Periodontal e Infecções Endodônticas. Rio de Janeiro: Medsi.

Vasconcelos KRF 2006. Avaliação in vitro da atividade antibacteriana de um cimento obtido da associação do óleo-resina in natura da Copaifera multijuga ao óxido de zinco e ao hidróxido de cálcio frente aos Streptococcus mutans e Streptococcus sanguinis. Manaus, 162p. Dissertação de Mestrado em Patologia Tropical - Faculdade de Ciências da Saúde, Universidade Federal do Amazonas.

Veiga Jr VF, Zunino L, Calixto JB, Patitucci ML, Pinto AC 2001. Phytochemical and antioedematogenic studies of commercial copaiba oils available in Brazil. Phytother Res 15: 476-480.

Veiga Jr VF, Pinto AC 2002. O gênero Copaifera L. Quim Nova 25: 273-286.

Veiga Jr VF, Zunino L, Patitucci ML, Pinto AC, Calixto JB 2006.The Inhibition of paw oedema formation caused by the oil of Copaifera multijuga Hayne and its fractions. J Pharm Pharmacol 58: 1405-1410.

Veiga Jr VF, Rosas EC, Carvalho MV, Henriques MGMO, Pinto AC 2007. Chemical composition and anti-inflammatory activity of copaiba oils from Copaifera cearensis Huber ex Ducke, Copaifera reticulate Ducke and Copaifera multijuga Hayne - A comparative study. J Ethnopharmacol 112: 248-254.

Watts A, Paterson RC 1987. Pulp-capping studies with analar calcium hydroxide and zinc oxide-eugenol. Int Endod J 20: 169-176. 